\title{
Emotional Intelligence, Leadership Styles Communication Patterns, and Job Satisfaction of College Principals
}

\author{
Afsheen Masood * \\ Rubab Mussarat** \\ Shama Mazahir***
}

\begin{abstract}
The quantitative method was adopted in order to measure the relationship among emotional intelligence, leadership styles, communication patterns and job satisfaction of college principals. Through cross sectional research design and by adopting convenient sampling procedure, the research participants (268) of age range between 40 - 65 years were accessed from different colleges of Lahore. The indigenous demographic questionnaire in addition to Multifactor Leadership Questionnaire (MLQ), by Bass and Avolio (2000), Job Satisfaction Survey (JSS), by Spector (1994), Emotional intelligence questionnaire (EI) by Goleman (1995) and Communication Pattern Questionnaire by Christensen and Heavey (1990) was used. The findings revealed that emotional intelligence, emotional management, motivating oneself, empathy and managing others' emotions were negatively related with passive avoidant leadership and positively correlated with communication patterns and job satisfaction. Also, self-awareness and both transformational and transactional leadership style were found to have a significant positive relationship with communication patterns and job satisfaction. Passiveavoidant leadership style was negatively correlated with communication patterns and job satisfaction. Furthermore, communication patterns were positively correlated with job satisfaction. The years of work experience, education, leadership style, communication patterns and age were found to be successful predictors of job satisfaction of college principals in Lahore. The findings carry strong implication for policy makers and
\end{abstract}

\footnotetext{
*Assistant Professor, Institute of Applied Psychology, University of the Punjab, Lahore, Pakistan

** Research Associate, Institute of Applied Psychology, University of the Punjab, Lahore.

***Institute of Applied Psychology, University of the Punjab, Lahore,
} 
for higher management in order to improve the quality of work life for college principals.

Keywords: Job Satisfaction, Communication patterns, leadership Styles, college principals

\section{Introduction}

Education is fundamental element for the development of any society. College teachers in Pakistan have greater tendency to leave their jobs due job dissatisfaction at their work places (Ahmed, 2010; Shaukat, \& Usman, 2010).

Colleges across the nation are in a state of transition in Pakistan as they are adapting to a changing, technologically rich and smart environment and are exposed to increased demands. External forces such as increased accountability, higher stakes-testing, changing family needs, the technological age, and society's demands upon colleges have left educators searching for leaders to help them through the maze of change and reform (Anari, 2012). In the rapidly changing college environment, efficient principals in the role of leaders are needed to make necessary changes while also developing a culture of shared responsibility and community (Hallinger \& Heck, 1998; Leithwood \& Jantzi, 1999; Wong, Wong and Law). Emotional intelligence is an important dimension that the college administrator has to develop in order to become successful. Emotional Intelligence is closely associated with life satisfaction, job performance, organizational commitment, job involvement, physical and mental health, absenteeism, turnover and labour grievances (Buitendach \& De Witte, 2005; Hoppkins, neil \& Williams, 2007).A growing number of academics and senior managers have recently recognized that emotional intelligence holds immense importance for the leader's effectiveness and success of an organization (Olsen, 1993; Buitendach \& De Witte, 2005).

Emotional intelligence is regarded as an important concept that leaders have to learn for the success of any organization. Daniel Goleman (1938) who brought the concept of emotional intelligence to the world's attention stated that effective leaders are alike in one crucial way. They all have a high degree of emotional intelligence. Furthermore, he explained that emotional intelligence is the sine qua non of leadership i.e. the most important ingredient (Goleman, 1998; Kafetsios, Nezlek \& Vassiou (2011).). Leader's emotional intelligence directly affects his or 
her effectiveness and success in an organization (Goleman, 1995; 1998; 1999).

According to Mayer \& Salovey (1997), emotional intelligence involves the ability to perceive accurately, appraise, and express emotion; the ability to access and/or generate feelings when they facilitate thought; the ability to understand emotion and emotional knowledge; and the ability to regulate emotions to promote emotional and intellectual growth. Goleman (1995) defined emotional intelligence as understanding one's own feelings, empathy for the feelings of others and the regulation of emotion in a way that enhances quality of living.

Mayer \& Salovey (1997) enlisted four domains of emotional intelligence. The first branch, identifying emotions, involves emotional recognition and expression. This branch focuses on self-awareness and emotional awareness. From a leadership perspective, identification of emotions is pivotal to a leader's understanding the needs and wants of others, as well as knowing the difference between what someone says and what he really means. The second branch involves the use of emotions to facilitate the thought process. This branch focuses on using emotions as part of the thinking process. Leaders can motivate through the use of emotions by generating enthusiasm and excitement in the work. The third branch, emotional understanding, includes the ability to recognize emotional causes and consequences, to understand relationships and complex feelings, to combine or blend emotions, to recognize contradictory states of emotions, and to comprehend transitions among emotions. Understanding emotional states and how people manage emotional information will allow the leader to assist others as they move through change processes. The fourth branch includes the abilities to acknowledge pleasant and unpleasant feelings and to manage emotions in self and others. Managing emotions allows leaders to deal with all of the stressors that are inherent to the job while also facilitating strong, working relationships that contribute to a positive work environment. Along with exhibiting leadership skills, leaders must be able to identify, use, understand and manage their own emotions, as well as the emotions of others (Caruso, Salovey, \& Mayer, 2003). First, the leader who can identify emotions has a high awareness not only of his/her own feelings, but also those of his/her followers. These leaders can express emotions accurately and identify false emotions. Second, it is important for the leader to have the ability to facilitate thought through the appropriate use of emotions. This ability reflects an understanding of how mood impacts thinking and decision making. This is important since the mood of the leader often sets the stage for the mood of the 
organization (Caruso et al., 2003; Mayer, Salovey, \& Caruso, 2002). These leaders also motivate through their use of emotions and can understand different perspectives. They encourage open-minded thinking and plan effectively. Third, a leader who understands emotions can recognize and develop relationships that are needed to lead others through change. Lastly, the leader must be able to manage his/her emotions by handling the stress that comes with the leadership position, as well as acting in the best interest of effective outcomes (Caruso et al., 2003; Mayer et al., 2002). These four branches of emotional intelligence are the framework for the ability theory of emotional intelligence as presented by Mayer and Salovey (1997).

Chemers (1997) defines leadership as a process of social influence in which a person can enlist the aid and support of others in the accomplishment of a common task. There are several leadership styles which are explained as follows: 1) Authoritarian leaders, also known as autocratic_leaders, provide clear expectations for what needs to be done, when it should be done, and how it should be done. This style of leadership is strongly focused on both commands by the leader and control of the followers. There is also a clear division between the leader and the followers. Authoritarian leaders make decisions independently with little or no input from the rest of the group. Researchers found that decision-making was less creative under authoritarian leadership. Lewin (1939) also found that it is more difficult to move from an authoritarian style to a democratic style than vice versa. Abuse of this style is usually viewed as controlling, bossy, and dictatorial.

Lewin's study (1939) found that participative leadership, also known as democratic leadership, is generally the most effective leadership style. 2) Democratic leaders offer guidance to group members, but they also participate in the group and allow input from other group members. In Lewin's study, children in this group were less productive than the members of the authoritarian group, but their contributions were of a much higher quality. Participative leaders encourage group members to participate, but retain the final say over the decision-making process. Group members feel engaged in the process and are more motivated and creative. Democratic leaders tend to make followers feel like they are an important part of the team, which helps foster commitment to the goals of the group.

3) Transformational leadership is often identified as the single most effective style. The style was first described in the late 1970s and later expanded upon by researcher Bernard (2010). Some of the key characteristics of his style of leadership are the abilities to motivate and 
inspire followers and to direct positive changes in groups. Transformational leaders tend to be emotionally intelligent, energetic, and passionate. They are not only committed to helping the group achieve its goals, but also to helping group members fulfill their potential. Research has revealed that this style of leadership is linked to higher performance and improved group satisfaction than other leadership styles. One study also found that transformation leadership was linked to improved well-being among group members (Jacobs, Pfaff \& Lehner, 2013).

4) The transactional leadership style views the leader-follower relationship as a transaction. By accepting a position as a member of the group, the individual has agreed to obey the leader. In most situations, this involves the employer-employee relationship and the transaction focuses on the follower completing required tasks in exchange for monetary compensation. One of the key benefits of this leadership style is that it creates clearly defined roles. People know what they are required to do and what they will be receiving in exchange for completing these tasks. It also allows leaders to offer a great deal of supervision and direction if it is needed. Group members may also be motivated to perform well in order to receive rewards. One of the biggest downsides is that the transactional style tends to stifle creativity and outof-the-box thinking (Bass, 1985; Burns, 1978).

Different authors have different approaches towards defining job satisfaction. Hoppock (1935) in its classical work on job satisfaction, defined job satisfaction as any combination of psychological, physiological and environmental circumstances that cause a person to say honestly that he is satisfied with his job (Hoppock, 1935). Vroom in his definition on job satisfaction focuses on the role of the employee in the workplace. Thus he defines job satisfaction as affective orientations on the part of individuals toward work roles which they are presently occupying (Vroom, 1964). Job satisfaction can be defined also as the extent to which a worker is content with the rewards he or she gets out of his or her job, particularly in terms of intrinsic motivation (Statt, 2004). The most-used research definition of job satisfaction is by Locke (1976), who defined it as a pleasurable or positive emotional state resulting from the appraisal of one's job or job experiences. Implicit in Locke's definition is the importance of both affect, or feeling, and cognition, or thinking. When we think, we have feelings about what we think. Since this research pertains to faculty in higher education, it would be pertinent to view job satisfaction from the principal perspective. In this regard, Evans (1997) defined teacher job satisfaction as a state of mind 
determined by the extent of the sense of personal achievement which the individual attributes to his/her performance of those components of his/her job which he/she values. In another study, Lortie (1975) interpreted job satisfaction as all rewards experienced in teaching which include extrinsic rewards meaning, prestige, income and power; intrinsic rewards referring to psychic rewards as in achievement of job values; and ancillary rewards. In this regard, Manger and Eikeland (1990) surmised that faculty who experienced dissatisfaction with extrinsic variables would leave their jobs. Munaf (2013) stated that teacher job satisfaction is an important variable resulting in dedicated teaching, administrative duties and research aimed at enhancing learning for students. This attitude of teachers would result in internal satisfaction leading to the achievement of organizational goals.

Fraser and Hodge (2000) stated that different organizational characteristics brought job satisfaction to different groups of workers. In this context, commitment to the organization meant different things to male and female workers resulting in dissimilar levels of commitment. Ridgeway (1997) concluded that job satisfaction for female faculty was not significantly predicted by organizational commitment. On the other hand, Oshagbemi (2000) stated that job satisfaction is not affected by gender, in fact, female faculty showed higher levels of job satisfaction than their male counterparts, especially those at higher academic ranks. A divergent point of view was expressed by Tack and Patitu (1992) in their statement that female faculty showed lower levels of satisfaction than male faculty in respect to their positions since their percentage in the faculty cohort was smaller, and their professional ranks were lower.

Research reveals that although principals may have little direct influence on student work, their indirect influence has a substantial effect on student engagement and achievement (Hallinger \& Heck, 1998; Leithwood, \& Jantzi, 2000; Marzano, Waters, \& McNulty, 2005). Marzano et al. (2005) conducted a meta-analysis of school leadership research, examining the effect of leadership on student achievement. This meta-analysis included 69 studies of 2,802 elementary, middle, high, K-8, and K-12 schools in the United States and other countries with similar cultures published between 1978 and 2001. Based on their analysis of the research,

Marzano, et al. (2005) concluded that there was a positive correlation between effective high school leadership and student achievement. Open and constant communication is vital during this quest for change. It is the principal who must communicate to his/her staff that the mission of the school is to educate all students (DiPaola, Tshannon- 
Moran, \& Walther-Thomas, 2004; Hawalah, 2005; McLaughlin \& Hyle, 2001). Communication lines must flow openly, not only from the top to bottom, but also from the bottom to top. The principal must monitor and attend to the needs of the school. It is the principal who guides the progression of school culture, and this culture is the underlying foundation for effectiveness (Flores, 2004; Lucas \& Valentine, 2002). The principal must involve the teachers in the decision-making process and encourage teachers to be leaders in the school (Leithwood \& Beatty, 2008). Sergiovanni (2005) states that the school leader must transform the school by uniting both administrators and teachers in higher-level common goals.

Wexley and Yukl (1984) stated that noteworthy cause of employee job satisfaction is the leadership style. Leader's characteristics impact employees and influence job satisfaction. Chen and Spector (1991) surmised that employee's self-esteem and job satisfaction may get influenced by the quality of the relationship between the leader and employee. Yukl (1971) concluded that considerate and supportive leaders increase job satisfaction of employees. On the other hand, hostile and unsupportive leaders cause stress for employees leading to low satisfaction (Wilkinson \& Wagner, 1993). Leader's instruction for the performance of work results in a sense of well-being for employees (Wexley \& Yukl, 1984). In this context, Robbins (2003) conjectured that employees leaving an organization would be fewer in the case of transformational leadership as compared to transactional leadership. Maeroff (1998) supported this view by stating that there existed a relationship between job satisfaction, transformational leadership and participative decision making. When leaders share information, keep channels of communication open and authorize, the level of job satisfaction is higher as compared to a condition of low teacher involvement in decision making which results in a low satisfaction level (Rice \& Schneider, 1994). Despite theoretical links there has been relatively little empirical research examining the relationship between emotional intelligence, leadership styles and job satisfaction. Carmeli (2003) stated that there have been relatively few empirical studies on emotional intelligence with specific rigor, especially in Asia.

Therefore, the main objective of this research is to attain a better understanding of the relationship between transformational leadership and emotional intelligence among principals as well as how effectiveness correlates with their transformational leadership behaviors and emotional skill abilities. The secondary objective is to identify the differences in the emotional intelligence, leadership styles, communication patterns and job 
satisfaction of male and female principals in Colleges of Lahore. This study will help to get a better understanding of emotional intelligence of principals and its relationship to leadership styles and job satisfaction. It can address the gaps currently existing in the literature especially in Pakistan and provide a more informed link between theory and practice.

Based on the literature review, the following research hypotheses were investigated in this study:

RH 1: There is likely to be a relationship in emotional intelligence, leadership styles, communication patterns and job satisfaction of principals among colleges of Lahore.

RH 2: Emotional intelligence, leadership styles, and communication patterns are likely to emerge as significant predictors of job satisfaction among college principals.

RH 3: Certain significantly correlated study variables and demographics are likely to predict the job satisfaction among college principals.

\section{Methodology}

\section{Research design}

The quantitative research was conducted in order to measure the emotional intelligence, leadership styles, communication patterns and job satisfaction of college principals. The researcher used survey research in order to analyze the behavior of the population of interest through the use of predetermined questions.

\section{Participants}

The research participants comprised 268 college principals (out of enlisted 2500 colleges), taken from different government colleges of Lahore through purposive sampling procedure, since choice of the sample was contingent upon certain predetermined characteristics of the respondents. Bothe male and female participants were included (48.34\% males and $51.66 \%$ females). The age range of the sample was 40 to 65 years, whereas mean age was 58.43 years. All the participants were approached personally by the researcher.

\section{Instruments}

Following measures were used in the current research:

1) Indigenous Demographic Questionnaire 
This was constructed indigenously by the researcher in order to seek information related to age, gender, education, qualification and number of years in job as principal.

2) Multifactor Leadership Questionnaire (MLQ).

The second questionnaire was the Multifactor Leadership Questionnaire (MLQ) based on the Full Range Leadership Model developed by Bass and Avolio (2000). The questionnaire is a short comprehensive assessment comprising 45 items, measuring a full range of leadership behaviors, predicting leader performance and possesses repeated validation by experts in the field of leadership. The reliability of the MLQ according to Bass and Avolio (2000) for each leadership factor ranges from 0.74 to 0.91 . The MLQ scale scores measure characteristics and behaviors of leaders.

3) Job Satisfaction Survey (JSS).

The third questionnaire used to test the job satisfaction level of faculty was the Job Satisfaction Survey (JSS) by Spector (1994) comprising 36 items and a nine facet scale. It assesses employee attitudes in regard to the job and aspects of the job. The reliability of the JSS ranges from 0.75 to 0.91 .

4) Emotional intelligence questionnaire (EI).

This self-assessment questionnaire is designed to get the test taker thinking about the various competencies of emotional intelligence as they apply to them. Goleman (1995) first brought emotional intelligence to a wide audience with his book of that name. He found that truly effective leaders are also distinguished by a high degree of emotional intelligence, which includes: (1) Self-awareness, (2) Managing emotions, (3) Motivating oneself, (4) Empathy, and (5) Social Skills. The ability to manage, influence and inspire emotions is also very important. This questionnaire consists of 50 items and is self-assessment questionnaire. It is marked on a scale of 1 to 5 i.e. Reliability ranges from .86.

5) Communication Pattern Questionnaire (CPQ)

An adapted and translated version of Christensen and Heavey (1990)'s condensed version of the Communication Pattern Questionnaire (CPQ), the CPQ-Short Form (CPQ-SF) was used. Originally developed for measuring communication patterns in spouses but later modified for use in employer-employee communication interaction, the scale inquires individuals to identify their typical communication patterns for two of the original three time periods: when an issue or problem arises and during discussions of the issue or problem. Items from the CPQ that pertain to these two time periods are used then to assess 
demand/withdraw and positive interactions as included in the CPQ$\mathrm{SF}$. The short form consists of 11 items, 5 items to assess symmetrical interaction pattern and 6 items to assess complementary interaction patterns in workers. Each of these patterns is assessed with two items that present the employer and employee alternating roles.

\section{Ethical considerations}

The researcher included a consent form constructed indigenously as per BERA (British Educational Research Association) ethical guidelines along with the survey instruments which enabled the prospective participants to comply or decline. The consent form assured confidentiality of data and non-disclosure of the information extended by the participants.

Procedure

The participants for the current study were contacted through the officials' data record accessed with due permission from education secretariat for collecting data from the recipient sample. The questionnaires along with the consent form were approved by research cell. Then appointment was obtained from the college principals and in face to face manner, the data was collected, by asking them to fill up the questionnaires individually. Every participant signed the consent form Performa and they were explained any ambiguity that they experienced. The response rate was 77.2 percent. This appears to be quite serious consideration as majority of the principals were apprehensive to reveal information about them.

\section{Data Analysis}

The result was analyzed by various descriptive and inferential analyses procedures. Pearson product moment correlation was sued to assess relationship strength and direction in the study variables. Linear regression analyses were used for finding the predictors of job satisfaction among college principals. 
Emotional Intelligence, Leadership Styles, Communication Patterns, and ...

\section{Results}

Table 1

Demographic Information of the Participants ( $\mathrm{N}=268)$

\begin{tabular}{lcc}
\hline Demographic Variables & $f$ & $\%$ \\
\hline Gender & 132 & \\
Male & 136 & 48.34 \\
Female & 51.66 \\
Age & 52 & \\
41-45 years & 24 & 31.14 \\
46-50 years & 24 & 14.2 \\
51-55 years & 50 & 14.2 \\
56-60years & 18 & 29.76 \\
61-65years & & 10.7 \\
Years of Work Experience & 64 & \\
2-12 years & 28 & 39 \\
13-22 years & 28 & 16.6 \\
23-32 years & 48 & 16.6 \\
33-42 years & & 28.6 \\
\hline
\end{tabular}

Following table shows that the Cronbach's alpha reliability of the scales was good.

Table 2

Descriptive statistics and internal consistencies of Scales

\begin{tabular}{lccccc}
\hline Scales & $\mathrm{k}$ & $\mathrm{a}$ & $\mathrm{M}$ & $\mathrm{SD}$ & Min-Max \\
\hline Job Satisfaction Survey & 36 & .70 & 28.12 & .92 & $4-20$ \\
Pay & 4 & .71 & 7.87 & .98 & $4-20$ \\
Promotion & 4 & .69 & 7.83 & 1.71 & $4-20$ \\
Supervision & 4 & .59 & 7.01 & 1.30 & $4-20$ \\
Fringe benefits & 4 & .76 & 7.09 & 1.06 & $4-20$ \\
Contingent rewards & 4 & .71 & 7.19 & 0.82 & $4-20$ \\
Operating procedures & 4 & .69 & 6.47 & 0.98 & $4-20$ \\
Coworkers & 4 & .86 & 6.59 & 1.25 & $4-20$ \\
Nature of work & 4 & .82 & 7.18 & 0.91 & $4-20$ \\
Communication & 4 & .52 & 7.02 & 2.44 & $4-20$ \\
Emotional Intelligence & 50 & .74 & 3.28 & 0.76 & $22-110$ \\
Self-awareness & 10 & .72 & 5.85 & 1.01 & $22-110$ \\
Managing emotions & 10 & .86 & 6.59 & 1.25 & $22-110$ \\
Empathy & 10 & .82 & 7.18 & 0.91 & $22-110$ \\
Motivating oneself & 10 & .52 & 7.02 & 2.44 & $22-110$
\end{tabular}


Afsheen, Rubab\& Shama

$\begin{array}{lccccc}\text { Social skills } & 10 & .74 & 3.28 & 0.76 & 22-110 \\ \text { Leadership Style Questionnaire } & 45 & .88 & 21.21 & 12.11 & 22-110 \\ \text { Transformational leadership } & 15 & .87 & 3.42 & 3.20 & 22-110 \\ \text { Transactional leadership } & 15 & .92 & 3.21 & 3.11 & 22-110 \\ \text { Passive-Avoidant leadership } & 15 & .85 & 2.12 & 2.98 & 22-110 \\ \text { Communication Pattern } & 11 & .74 & 3.28 & 0.76 & 11-99 \\ \text { Questionnaire } & & & & & \\ \text { Symmetrical Interaction Pattern } & 05 & .62 & 2.43 & 0.33 & 11-99 \\ \quad \text { Complementary Interaction } & 06 & .72 & 5.85 & 1.01 & 11-99 \\ \begin{array}{l}\text { Pattern } \\ \hline\end{array} & & & & & \end{array}$

Pattern

k: total number of items; min-max: minimum and maximum scores possible on the measuring tool;

$\alpha$ : reliability coefficient; $M=$ Mean; SD: Standard deviation

It was hypothesized that there is likely to be a relationship in emotional intelligence, communication patterns, leadership style and job satisfaction of college principals. The results are presented in table 3

Table 3

Correlations Coefficients in emotional intelligence, communication patterns, leadership style and job satisfaction

\begin{tabular}{|c|c|c|c|c|c|c|c|c|c|c|}
\hline Variables & 2 & 3 & 4 & 5 & 6 & 7 & 8 & 9 & 10 & 11 \\
\hline $\begin{array}{l}\text { 1. Emotional } \\
\text { Intelligence }\end{array}$ & $.57^{* *}$ & $.34 * *$ & $.27 * *$ & $.43^{* *}$ & .21 & .15 & .06 & $-.17 * *$ & $.67 * *$ & $.53 * *$ \\
\hline 2. Self-awareness & & $.56^{*}$ & .54 & $.63^{* *}$ & $.66^{* *}$ & $.76^{* *}$ & .65 & .34 & $.57 * *$ & $.72 * *$ \\
\hline $\begin{array}{l}\text { 3. Emotional } \\
\text { management }\end{array}$ & & & $.66 * *$ & $.43 * *$ & $.57 * *$ & $.62 * *$ & .67 & $-.87^{* *}$ & $.77 * * *$ & $.65 * * *$ \\
\hline 4. Motivating oneself & & & & $.57 * *$ & $.63 * * *$ & $.77 * * *$ & $.56^{*}$ & $-.67 *$ & $.56^{* *}$ & $.42 * *$ \\
\hline 5. Empathy & & & & & $.67 * *$ & $.87 * * *$ & $.56^{* *}$ & $.56 * *$ & $.67 * *$ & $.53 * *$ \\
\hline $\begin{array}{l}\text { 6. Managing others } \\
\text { emotions }\end{array}$ & & & & & & $.67 *$ & $.76^{* * *}$ & $.73 * * *$ & $.54 * *$ & $.75 * *$ \\
\hline $\begin{array}{l}\text { 7.Transformational } \\
\text { leadership }\end{array}$ & & & & & & & .19 & .11 & $.54 * *$ & $.44 * *$ \\
\hline $\begin{array}{l}\text { 8. Transactional } \\
\text { leadership }\end{array}$ & & & & & & & & .31 & $.67^{*}$ & $.37 *$ \\
\hline $\begin{array}{l}\text { 9. Passive-avoidant } \\
\text { leadership }\end{array}$ & & & & & & & & & $-.78 * *$ & $-.43^{* *}$ \\
\hline $\begin{array}{l}\text { 10. communication } \\
\text { patterns } \\
11 \text {. Job Satisfaction }\end{array}$ & & & & & & & & & & $.82 * * *$ \\
\hline
\end{tabular}

${ }^{*} \mathrm{p}<.05, * * \mathrm{p}<.01, * * * \mathrm{p}<.001$

Results revealed that emotional intelligence, emotional management, motivating oneself, empathy and managing others emotions were negatively related with passive avoidant leadership and positively correlated with communication patterns and job satisfaction. Also, self-awareness and both transformational and transactional 
leadership style were found to have a significant positive relationship with communication patterns and job satisfaction. Passive-avoidant leadership style was negatively correlated with communication patterns and job satisfaction. Furthermore, communication patterns were positively correlated with job satisfaction.

Table 4

Analysis of Variance for Linear Regression with Years of Work Experience and Age as Predictor of Job Satisfaction

\begin{tabular}{llllll}
\hline Model & SS & df & MS & F & Sig. \\
\hline Regression & 1722.45 & 2 & 861.22 & .04 & .46 \\
Residual & 163744.34 & 266 & 1674.77 & & \\
Total & 165466.88 & 268 & & & \\
\hline
\end{tabular}

a. Predictors (Constant)

b. Dependent Variable: Job Satisfaction Total

The test reveals significant findings at the level of significance less than 0.05. The Linear Regression model with years of experience and age as predictors of job satisfaction of principals is significant as the $p$ value reads $p>0.05$. The committed Type 1 error alpha is 0.456 . Thus it is concluded that years of work experience and age are successful predictors of job satisfaction of college principals in Lahore.

It was hypothesized that certain demographics and study variables are likely to predict job satisfaction in college principals.

Table 5

Multiple regression analyses to find the predictors of Job satisfaction $\mathrm{N}=268$

\begin{tabular}{lcccc}
\hline Independent Variables & S.E & $\beta$ & $\mathrm{t}$ & $\mathrm{p}$ \\
\hline Emotional Intelligence & .04 & 0.04 & 2.76 & $0.01^{* *}$ \\
Leadership styles & .04 & 0.31 & 4.34 & $0.00^{* *}$ \\
Communication patterns & .04 & 0.05 & 9.78 & $0.03^{*}$ \\
Years in this position & .03 & 0.15 & 3.43 & 0.00 \\
Relationship with workers & .05 & 0.04 & 4.32 & 0.13 \\
Education & .04 & 0.54 & 0.99 & 0.43 \\
\hline
\end{tabular}

$\mathrm{N}=268$, Adjusted R Square $=0.500, \mathrm{~F}=32.250$, Durbin-Watson= 2.191, overall model, $\alpha=0.05$

Regression table reveals the total and relative amount of variation in dependent variable due to the independent variable. Table 5 shows the value of Adjusted $\mathrm{R}^{2}$ is 0.500 . This value indicates that there is almost $50 \%$ variation in dependent variable (job satisfaction) due to a one unit change in independent variables. A number that tests for autocorrelation 
in the residuals from a statistical regression analysis is known as DurbinWatson value. The Durbin-Watson value is 2.191 that is significant. Results expose that the $\mathrm{F}$ value is 32.250 at 0.00 alpha levels which shows that the model is significant. Hence emotional intelligence is highly significant predictor of job satisfaction whereas leadership style and communication patterns emerge as moderate yet significant predictors of job satisfaction among college principals.

\section{Discussion and Conclusion}

The study was conducted to investigate emotional intelligence, leadership styles and job satisfaction in principals of colleges. It was expected that there would be a relationship among emotional intelligence, leadership styles, communication patterns and job satisfaction of principals of colleges in Lahore and also that the means scores of emotional intelligence, communication patterns style and leadership styles would significantly differ across male and female principals in colleges of Lahore. It was also expected that certain significantly related study variables and demographics would predict the job satisfaction among college principals.

The results revealed that emotional intelligence, emotional management, motivating oneself, empathy and managing others emotions were negatively related with passive avoidant leadership and positively correlated with communication patterns and job satisfaction. This shows that emotionally intelligent principals would be making lesser use of passive-avoidant leadership style and would be more satisfied with their job. The reason behind this might be due to the reason that individuals higher in emotional intelligence are believed to be in control of their emotions and can regulate their own and others' emotions quite well. Thus, by managing others' emotions appropriately, especially of their coworkers and subordinates, they tend to use passive-avoidant relationship at the minimum level and thus with such dynamic and active response patterns they get more satisfied with their jobs. This finding is well supported by the findings in which it was reported that employee who is well-informed by their supervisor in their respective organization, is more likely to understand their job requirements and expectations of their contribution to an organization's success ((Hindi et al., 2004; Downs and Adrian, 2004). Results also revealed that self-awareness in addition to transformational and transactional leadership styles have a significant positive relationship with communication patterns and job satisfaction. Passive-avoidant leadership style was negatively correlated 
with communication patterns and job satisfaction. Furthermore, communication patterns were positively correlated with job satisfaction. Another significant finding showed that years of work-experience and age were successful predictors of job satisfaction of college principals. This illustrates that college principals who are experienced and have older ages are likely to have better communication patterns and may adopt effective leadership skills. The results also revealed that emotional intelligence, leadership styles and communication patterns significantly predicted job satisfaction of college principals in Lahore. Transformational leadership emerges as being the most effective leadership style in colleges. In comparison to past few decades, the clearer focus now lies in democratic leadership as being more effective than transformational ones to run educational institutional set ups. Yet here this is evident that transformational leadership appears better than democratic leadership due to rigid functioning patterns of colleges. This finding stands in strong corroboration of findings by Bailey (2002) and the empirical result of Awang, Ahmad, \& Zin (2010). In a collective society like Pakistan, the faculty members are not much autonomous and they generally expect their leader in the role of college principal to take decision by themselves (Hofstede, 2001; House et al. 2004), and there is a culture of absolute compliance in government set ups wherein the subordinates are expected by their heads to comply, 'obey' and 'work' without challenging their decisions (Shah, 2009). The above findings are very much in support of the results acquired in the current research.

In a nutshell, the relationship between leadership styles, communication pattern and job satisfaction exist in the light of current findings, however this may vary in its degree with reference to different leadership styles and contextual factors where this leadership exist. The interplay between leadership style, communication patterns and job satisfaction is better understood when this is judged by the organizational and cultural context, therefore there may not be one leadership style that might enhance the job satisfaction in different organizational and cultural set ups. This research is limited due to being focalized to small sample size and also for being spaced into one city; thus it is suggested that such a research study in future should be replicated and this empirical investigation may be conducted with larger sample by inculcating participants from multiple cities in order to increase its generalizability. This is also suggested that inculcation of qualitative method for data acquisition may add depth and better insight into the intricate phenomenon of leadership styles, communication patterns and job satisfaction. 


\section{References}

Ahmed, I., Shaukat, Z; \&Usman, A. (2010). International Journal of Business and Management 5 (3), 70.

Anari, N. N. (2012). Teachers: Emotional intelligence, job satisfaction, and organizational commitment. Journal of Workplace Learning, 24(4), 256-269.

Awang, Z., Ahmad, J. H., \&Zin, N. M. (2010). Modelling Job Satisfaction and Work Commitment among Lecturers: A Case of UiTM Kelantan. Journal of Statistical Modeling and Analytics, 1(2), 45-59.

Bailey, N. I. (2002). The Relationship Between Organizational Climate and Job Satisfaction as Reported by Branch Campus Executive Officers in Multi-Campus College Systems, Unpublished Doctoral Dissertation, University of Florida, UMI Dissertation Service. Bass, B. M. (1985). Leadership and Performance. NY: Free Press.

Buitendach, J. H., \& De Witte, H. (2005).Job insecurity, extrinsic and intrinsic job satisfaction and affective organizational commitment of maintenance workers in a parasternal. South African Journal of Business Management, 36(2), 27-37.

Bass, B. M., \& Avolio, B. J. (2000). MLQ Multifactor Leadership Questionnaire (2nd Ed.). Redwood City, CA: Mind Garden.

Bass, B. M. (1985). Leadership and performance beyond expectations. New York: Free Press.

Bernard, H. R., \& Ryan, G. W. (2010). Analyzing qualitative data: Systematic approaches. Los Angeles, CA: Sage.

Burns, J. M. (1978). Leadership. New York: Harper \& Row.

Carmeli, A. (2003). The relationship between emotional intelligence and work attitudes, behavior, and outcomes: An examination among senior managers. Journal of Managerial Psychology, 18(8), 788-813.

Chen, P. Y., \& Spector, P. E. (1991). Negative affectivity as the underlying cause of correlations between stressors and strains. Journal of Applied Psychology, 76, 398-407.

Caruso, D. R., Salovey, P., \& Mayer, J. (2003). Emotional intelligence and emotional leadership. In P. Salovey, M. A. Brackett, \& J. D. Mayer, 
Emotional Intelligence, Leadership Styles, Communication Patterns, and ...

(Eds.), Emotional intelligence: Key readings on the Mayer and Salovey model (pp. 305-325). Port Chester, NY: Dude Publishing.

Chemers, M. (1997). An integrative theory of leadership. Lawrence Erlbaum Associates, Publishers.

Christensen, A., \&Heavey, C. L. (1990). Gender and social structure in the demand-withdraw pattern of marital conflict. Journal of Personality and Social Psychology, 59, 73-81.

DiPaola, M., Tschannon-Moran, M., \& Walther-Thomas, C. (2004). School principals and special education: Creating the contact for academic success. Focus on Exceptional Children, 37(1), 54-65.

Downs CW \& Adrian AD (2004) Assessing organizational communication: Strategic communication audits. New York, the Guilford Press.

Evans, J. (April 1997). Ultrasonic comes of age for solids and liquids. In Tech, 38-42.

Flores, M. A. (2004). The impact of school culture and leadership on new teachers' learning in the workplace. International Journal of Leadership in Education, 7(4), 297-318.

Goleman, D. (1995). Emotional intelligence: Why it can matter more than IQ. New York: Bantam Books.

Goleman, D. (1998). Working with emotional intelligence. New York: Bantum Books

Goleman, D. (1999). Working with emotional intelligence. London, United Kingdom: Bantam Books.

Goleman, Daniel. (1995). Emotional intelligence. New York: Bantam.

Hallinger, P., \& Heck, R. (1998). Exploring the principal's contribution to school effectiveness. School Effectiveness and School Improvement, 9(2), 157-191.

Hawalah, I. (2005). The relationship between effective communication of high school principals and school climate. Educational Administration, 126(2), 334-345.

House R.J. et al. (eds.), Culture, Leadership, and Organizations: The GLOBE Study of 62 Societies. Thousand Oaks, CA: Sage, 2004. 
Hofstede, G.H., Culture's Consequences: International Differences in WorkRelated Values. Thousand Oaks, CA: Sage, 1980 (revised and expanded in 2001).

Hindi, N. M., Miller, D. S. and S. E. Catt, 2004. "Communication and Miscommunication in Corporate America: Evidence From Fortune 200 Firms”, Journal of Organizational Culture, Communications and Conflict 8(2), pp. 13-26.

Hopkins, M. M., O'Neil, D. A., \& Williams, H. W. (2007). Emotional intelligence and board governance: Leadership lessons from the public sector. Journal of Managerial Psychology, 22(7), 683-700.

Hagedorn, L. S. (2000). Conceptualizing faculty job satisfaction: Components, theories, and outcomes. New Directions for Institutional Research, 105, $5-20$

Hoppock, R. (1935). Job Satisfaction, Harper and Brothers. New York: Sync Publishing.

Jacobs, C., Pfaff, H., \&Lehner, B. (2013). The influence of transformational leadership on employee well-being: results from a survey of companies in the information and communication technology sector in Germany. Journal of Occupational and Environmental Medicine, 55(7), 772-778.

Kafetsios, K., Nezlek, J. B., \&Vassiou, A. (2011).A multilevel analysis of relationships between leaders' and subordinates' emotional intelligence and emotional outcomes. Journal of Applied Social Psychology, 41(5), $1121-1144$

Leithwood, K., \& Beatty, B. (2008).Leading with teacher emotions in mind. Thousand Oaks, CA: Corwin Press.

Lortie, D. 1975. Schoolteacher: A Sociological Study. London: University of Chicago Press.

Leithwood, K., \&Jantzi, D. (1999a). The effects of transformational leadership on organizational conditions and student engagement with school. Journal of Educational Administration, 38(2), 112-129

Leithwood, K., \&Jantzi, D. (2000). Principal and teacher leadership effects: A replication. School Leadership \& Management, 20(4), 415- 434.

Lewin, K., (1939). Patterns of aggressive behavior in experimentally created 'social climates.' Journal of Social Psychology, 10, 271-299. 
Emotional Intelligence, Leadership Styles, Communication Patterns, and ...

Locke, E. A. (1976). The nature and causes of job satisfaction. In M. D. Dunnette (Ed.), Handbook of industrial and organizational psychology (pp. 1297-1349). Chicago: Rand McNally.

Lucas, S. E., \& Valentine, J. W. (2002). Transformational leadership: Principals, leadership teams and school culture. Paper presented at the Annual Meeting of the American Educational Research Association. Retrieved March 29. 2008.

Marzano, R., Waters, T., \& McNulty, B. A. (2005). School leadership that works: From research to results. Alexandria, VA: ASCD

Mayer, J. D., \&Salovey, P. (1997). What is emotional intelligence? In P. Salovey, M. A. Brackett, \& J. D. Mayer (Eds.), Emotional intelligence: Key readings on the Mayer and Salovey model (pp. 29-59). Port Chester, NY: Dude Publishing.

Maeroff, G. (Ed). (1998). imaging education: The media and schools in America. New York: Teachers College.

Mayer, J. D., Salovey, P., \& Caruso, D. R. (2002).Mayer-Salovey-Caruso Emotional Intelligence Test (MSCEIT) User's Manual. Toronto: MultiHealth Systems.

McLaughlin, L., \&Hyle, A. E. (2001). The school principal as change agent: An explanatory case study. Paper presented at the Annual Meeting of the American Educational Research Association.

Manger, T., \& Eikeland, O.J. (1990). Factors Predicting Staff's Intentions to Leave the University. Higher Education, Vol. 19, No. 3, pp. 281-291.

Munaf, S. (2009). Motivation, Performance and Satisfaction among University Teacher; Comparing Public and Private Sectors in Pakistan and Malaysia. South Asian Journal of Management.

Oshagbemi, T. (2000). Gender differences in the job satisfaction of university teachers. Women in Management Review, 15(7), 331-343.

Robbins, S.P.,Odendaal, A., and Roodt, G. (2003). Organizational Behavior. Global and Southern African Perspectives (9th Ed.). Cape Town: Pearson Education.

Rice, E. M., \& Schneider, G. T. (1994). A decade of teacher empowerment: An empirical analysis of teacher involvement in decision-making, 19801991. Journal of Educational Administration, 32(1), 43-58. 
Ridgeway, Cecilia L. 1997. "Interaction and the Conservation of Gender Inequality: Considering Employment." American Sociological Review 62(2): 218-35.

Sergiovanni, T. (2005). Adding value to leadership gets extraordinary results. Educational Leadership, 47(8), 23-25.

Spector, P.E. (1994). Job satisfaction survey. Tampa, FL: University of South Florida, Department of Psychology.

Statt, D. (2004). The Routledge Dictionary of Business Management. ( $3^{\text {rd }}$ Ed.). Routledge Publishing: Detroit.

Shah, S. M. A., Lagari, M. K., \& Rani, D. I. (2012). Impact of organizational culture on the employee's job satisfaction; a study of faculty members of private sector universities of Pakistan. Asian Journal of Business and Management Sciences, 1(12), 92-101.

Tack, M.W., and C.L. Patitu. 1992. Faculty job satisfaction: women and minorities in peril. ASHE-ERIC higher education report no. 4. Washington, DC : The George Washington University.

Vroom, V. H. (1964). Work and motivation. John Wiley and Sons: New York.

Wong, C.S., Wong, P. M., \& Law, K. S. (2002). The interaction effect of emotional intelligence and emotional labour on job satisfaction: A test of Holland's classification of occupations in Hong Kong.

Wilkinson, A.D. and Wagner, R.M. (1993) Supervisors Leadership Styles and State Vocational Rehabilitation: Counselor Job Satisfaction and Productivity. Rehabilitation Counseling Bulletin, 37, 15-24.

Wexley, K., and Yukl, G. (1984). Organizational Behavior and Personnel Psychology. Homewood, IL: Richard D. Irwin

Yukl, G. A. (1971). Toward a behavioral theory of leadership. Organizational Behavior and Human Performance, 6, 414 - 440.

Received on: 13.11.2015

Revised on:26.4.2016

Accepted on: 10.05.2016 